\title{
Singuagens
}

\section{BELA, RECATADA E DO LAR: ANÁLISE DE UM ARTIGO DE OPINIÃO SOB O ENFOQUE DA PERSPECTIVA DE GÊNERO AUSTRALIANA}

\author{
Caroline Teixeira Bordim (UFSM) \\ Gessélda Somavilla Farencena (UFSM)
}

\begin{abstract}
RESUMO: Este trabalho tem como objetivo verificar qual gênero se faz presente em um artigo de opinião de autoria de Edegar Pretto, publicado no jornal Zero Hora, a partir da aplicação de categorias da Teoria de Gênero e Registro (MARTIN; ROSE, 2008; MARTIN, 2009; ROSE; MARTIN, 2012). Para isso, em um primeiro momento, são analisadas as variáveis de Registro do texto A bela, recatada e do lar, de 26 de abril de 2016. Em seguida, a partir da aplicação de categorias para identificação do propósito comunicativo e das etapas e fases que ele seleciona, apontamos o gênero empregado e a Estrutura Esquemática que o realiza. Como resultado, pode ser apontada a escolha pelo gênero exposição de opinião para manifestar o ponto de vista do autor sobre o machismo, o que estaria sendo utilizado por algumas pessoas para atingir a presidente Dilma Rousseff.
\end{abstract}

Palavras-chave: Linguística Sistêmico-Funcional. Teoria de Gênero e Registro. Artigo de opinião.

ABSTRACT: This work aims to identify what is the genre present in an opinion article from Edegar Pretto, published in the newspaper Zero Hora, from the application of the categories from the Genre and Register Theory (MARTIN; ROSE, 2007; MARTIN, 2009; ROSE; MARTIN, 2012). For such, at first, the variables of Register in the text in the text $A$ bela, recatada e do lar, on April 26th, 2016 are analyzed. Afterwards, from the application of the categories for the identification of the communicative purpose and the phases or stages that it selects, pointing out the genre used and the Schematic Structure that it belongs to. As a result, it can be identified the choice for the genre of opinion exposition to reveal the author's point of view about the chauvinism which has been used by some people to affect President Dilma Rousseff.

Keywords: Systemic-Functional Grammar. Genre and Register Theory. Opinion Article.

\section{INTRODUÇÃO}

A perspectiva de gênero australiana é ainda relativamente pouco estudada no contexto brasileiro. Embora sejam encontrados trabalhos que a tomam como base teórica, como os de Silva e Espindola (2013), Fuzer, Gerhardt e Gonçalves (2014) e Farencena (2016), estes são recentes e buscam inseri-la em nosso contexto. No intuito de nos somar a essas pesquisas, este trabalho tem como propósito identificar o gênero utilizado em um artigo de opinião sob enfoque da perspectiva de Gênero e Registro (MARTIN; ROSE, 2008; MARTIN, 2009; ROSE; MARTIN, 2012). 


\section{S Linguagens}

Para atender a esse propósito, analisamos um artigo de opinião de autoria de Edegar Pretto, que tem como título A bela, recatada e do lar. Para a melhor compreensão do texto e para a realização da pesquisa, empregamos a descrição do registro, identificamos o propósito comunicativo do texto e a Estrutura Esquemática do Gênero.

Além desta introdução, o artigo está dividido em cinco seções. Inicialmente apresentamos algumas características do artigo de opinião. Em seguida, abordamos o gênero na perspectiva da Escola de Sydney. Na seção 3, identificamos os métodos utilizados para a realização da pesquisa. Após, dividida em duas subseções, trazemos a análise contextual e linguística, seguida das considerações finais.

\section{ARTIGO DE OPINIÃO}

Com características peculiares que, conforme Uber (2008), identificam-no como um texto argumentativo, o artigo de opinião pode circular em vários locais, como no rádio, na TV, nas revistas e nos jornais. Segundo Melo (2003) o artigo de opinião pode ter duas definições: 1) a do senso comum, que lhe atribui o sentido de matéria publicada em jornal ou em revista, e 2) a de matéria jornalística em que alguém desenvolve uma ideia e apresenta sua opinião. Ao artigo jornalístico, conforme Vivaldi (1999, apud MELO, 2003, p.122), dois elementos são específicos e indispensáveis: atualidade e opinião.

Cada escritor procura ter um jeito próprio de escrever seus textos, adotando elementos linguísticos que possam representá-lo. Para que o artigo consiga cumprir o seu papel, é preciso que apresente bons argumentos sustentados por verdades e opiniões, pois, como salienta Uber (2008, p. 7), "para se ter opinião é preciso ter informação", logo, "é absolutamente impossível opinar sem conhecer os fatos". Como complementação às informações apresentadas, o texto pode trazer vozes externas (citações de outros autores, trechos de músicas, trechos de outros textos) que contribuem para fortalecer os argumentos do autor.

Também contribuindo para a construção da argumentação, vários recursos linguísticos fazem parte da estruturação de um artigo de opinião, dentre eles a construção do discurso quase sempre em terceira pessoa, o emprego de conjunções adversativas e a utilização de 


\section{$\checkmark$ Linguagens}

modalizadores (UBER, 2008, p. 6). A escolha desses recursos e das palavras que os realizam, tal como aponta a autora, não é por acaso, mas estão atreladas à intenção do autor ao produzir o texto.

Sempre que um texto é produzido, explica Uber (2008, p. 6), as ideias devem ser organizadas de maneira que se tenha uma sequência, uma conexão entre as partes, formando um sentido geral no texto. No caso dos textos argumentativos e, como tal, dos artigos de opinião, o sentido global, segundo a autora, é dado pela conjunção de três etapas: a introdução, o desenvolvimento e a conclusão. Assim organizado o texto, a apresentação do tema, da tese e dos argumentos é essencial, já que são elementos fundamentais à argumentação.

Conhecer o artigo de opinião "em todos os seus elementos composicionais, estilo, marcas linguísticas e enunciativas requer muitas leituras, estudos árduos.” (UBER, 2008, p. 22). Cientes disso, buscamos, com este trabalho, compreender melhor o artigo de opinião e, para isso, buscamos apoio na perspectiva de gênero australiana, abordada na seção seguinte.

\section{GÊNERO NA PERSPECTIVA DA ESCOLA DE SYDNEY}

Na perspectiva australiana, o termo gênero é usado para abarcar cada tipo de atividade linguisticamente realizada que faz parte de nossa cultura (ROSE, 2011). Para o autor, gênero é uma atividade proposital, orientada a um objetivo e desenvolvida em etapas, na qual os falantes se envolvem como membros de uma cultura.

Nessa perspectiva, são apontados vinte e um gêneros, organizados conforme a função social que desempenham. Conforme Rose e Martin (2012), com a função de entreter, há os gêneros pertencentes à família das estórias. Voltadas ao propósito de informar, estão as famílias das histórias, das explicações, dos relatórios e dos procedimentos. Destinadas a avaliar, há as famílias de reação a textos e do argumentar. Integrando esta última, está o gênero exposição de opinião, que tem como propósito defender um ponto de vista e, para isso, constitui-se pelas etapas Tese, Argumentos e Reiteração da tese.

Para Gouveia (2014), um texto ocorre sempre em dois contextos simultâneos, ou seja, em um contexto de situação dentro de um contexto de cultura. $\mathrm{O}$ contexto de cultura informa 


\section{Linguagens \& Cidadania}

os textos que, por sua vez, são produtos dos sistemas linguísticos postos em funcionamento em diferentes situações interativas. Na interação instaurada no contexto de situação, pode-se observar mais diretamente o conteúdo da ação social (campo), o envolvimento dos participantes (relação) e a forma de organização da língua (modo).

Ao se referir a textos, Halliday (1989) considera-os não apenas como produto, mas também atrelados a contexto de cultura e o contexto de situação nos quais os textos são produzidos. Quando é utilizado um gênero, são feitas escolhas das variáveis de registro (campo, relação e modo), como: com quem se comunicar, que meio será utilizado, de que tipo de linguagem será feito uso.

Todas essas decisões no âmbito do registro são fundamentais, já que somente após tomadas tais decisões é que se passa à interação (HALLIDAY, 1989). Por essa razão, assim como explicam Eggins e Martin (1999), a teoria de Gênero permite-nos trazer para a consciência conhecimentos culturais compartilhados a partir da descrição de inúmeras formas linguísticas utilizadas para interagir socialmente, além de nos permitir refletir criticamente sobre como a cultura nos envolve.

Nesse sentido, na seção seguinte, apresentamos a metodologia adotada para entendermos as escolhas feitas para interagir socialmente por meio de um artigo de opinião.

\section{METODOLOGIA}

Neste artigo, o ponto de partida da análise é o artigo de opinião A bela, recatada e do lar publicado dia 26 de abril de 2016, no jornal Zero Hora online. De autoria de Edegar Pretto, um político filiado ao Partido dos Trabalhadores, o texto apresenta como tema o machismo, algo polêmico e bastante enfatizado durante o processo de impeachment da presidenta Dilma Rousseff, principalmente, quando da definição de seu afastamento do cargo (31 de agosto de 2016), período em que o texto analisado foi produzido.

Definido o texto, com o propósito de verificar qual o gênero utilizado pelo autor ao produzir seu artigo de opinião, a análise seguiu os seguintes passos: 


\section{Linguagens \& Cidadania}

1. Análise do registro: descrição das variáveis do contexto de situação - campo, relações e modo;

2. Identificação do propósito comunicativo do texto;

3. Identificação da Estrutura Esquemática de Gênero: análise das etapas e fases que a compõem.

\section{ANÁLISE CONTEXTUAL E LINGUÍSTICA}

Nesta seção, são apresentadas as análises desenvolvidas no intuito de identificar qual o gênero é empregado na constituição do exemplar de artigo de opinião em análise. Para isso, na seção 4.1, apresentamos a descrição do registro e, na seção 4.2, empreendemos a análise linguística do texto.

\subsection{Análise do registro}

Ao se observar o campo do texto, ou seja, o que está acontecendo, verifica-se que $A$ bela, recatada e do lar é um texto que realiza uma prática social opinativa ("defendemos", "nos revoltamos"). Para opinar, de modo especial sobre o machismo ("machista", "preconceito"), o artigo parte de outros textos jornalísticos, especificamente de reportagens das Revistas Veja e Isto é.

Analisando a segunda variável situacional, verificamos que, no texto, a relação estabelecida entre os participantes é de proximidade, como demonstram os verbos na primeira pessoa do plural (“aceitamos", "vemos", "revoltamos", "defendemos"), que servem tanto para inserir o leitor quanto expor o autor no texto. Tendo em vista que o artigo foi publicado no jornal Zero Hora, jornal que circula no estado do Rio Grande do Sul, supõe-se que os possíveis leitores sejam assinantes do jornal e/ou leitores do site da Zero Hora.

No que se refere ao modo, o uso da linguagem culta é um aspecto linguístico bem marcado no texto, atribuindo-lhe ar de formalidade, o qual está associado à seção e ao veículo em que é publicado. O tempo pretérito perfeito/imperfeito é empregado para relatar alguns fatos que ocorreram ("afirmava", "reforçou”, "publicou”, “definiu”, "tinha”). Além disso, o 


\section{Singuagens}

texto apresenta vozes externas que proporcionam credibilidade (matéria sobre o "descontrole emocional de Dilma Rousseff", da revista Isto é, e a reportagem sobre Marcela Temer, publicada na revista Veja.

Conhecido o registro do texto em discussão, passamos à análise textual, a fim de verificar como o contexto se manifesta na definição do gênero.

\subsection{Análise da estrutura esquemática do gênero}

O artigo de opinião A bela, recatada e do lar, de Edegar Pretto, aborda o machismo não apenas sob o viés do preconceito, mas também como um meio utilizado por alguns brasileiros para atacar Dilma Rousseff. Como petista e, portanto, aliado da Presidenta, o autor manifesta e defende seu ponto de vista sobre o tema por meio do gênero exposição de opinião, em que a Tese, apresentada abaixo, é defendida por dois Argumentos e Reiterada ao final do texto.

\footnotetext{
Tese $\quad$ O machismo também faz parte da estratégia para desconstituir a presidenta Dilma, eleita democraticamente por 54 milhões de brasileiros e brasileiras.
}

Ao declarar que "o machismo também faz parte da estratégia para desconstruir a presidenta", o autor expõe como ele vê a relação entre a "presidenta eleita democraticamente", o "machismo" e as investidas daqueles que são contrários ao seu governo. Dito de outro modo, a afirmação de que o machismo é usado para atingir Dilma Rousseff é a Tese apresentada por Pretto e defendida na sequência do texto, na etapa dos Argumentos.

Organizada em duas fases, a argumentação baseia-se em publicações de revistas nacionais. No primeiro argumento, o autor cita a reportagem da Revista Isto é, conforme o excerto abaixo. 


\section{S Linguagens}

\begin{tabular}{|c|l|}
\hline Desde a campanha eleitoral, Dilma sofre ataques machistas. Algumas semanas atrás \\
nos revoltamos com matéria da revista Isto é, que afirmava que a presidenta estava \\
desequilibrada e sem condições emocionais para conduzir o país, inclusive quebrando móveis \\
dentro do palácio.
\end{tabular}

Como que para exemplificar uma situação em que o machismo foi utilizado como "estratégia para desconstruir a presidenta" e, com isso, comprovar a Tese, o autor utilizada como argumento a reportagem da revista Isto é, que afirmava que "a presidenta estava desequilibrada e sem condições emocionais para conduzir o país".

Com a referida reportagem, avalia Pretto, a capacidade das mulheres de exercer o poder político foi posta em dúvida, já que, segundo a revista, elas "são descontroladas emocionalmente". Esse perfil construído para as mulheres, por sua vez, corrobora a constatação do autor de que "q[Q]uando o assunto é política, as mulheres têm pouco espaço para serem ouvidas, e são comuns os casos de machismo e preconceito" e, por conseguinte, sua Tese.

No segundo argumento, o autor novamente parte de uma reportagem, agora publicada pela Revista Veja, como verificamos a seguir.

\begin{tabular}{|c|c|}
\hline & $\begin{array}{c}\text { Após a votação do impeachment da presidenta Dilma na Câmara dos Deputados, } \\
\text { onde também assistimos muitas falas misóginas, a revista Veja publicou reportagem com } \\
\text { Marcela Temer, esposa de Michel Temer, e já na manchete a definiu como bela, recatada e } \\
\text { do lar. O texto tinha aparente pretensão de elogio ao fato de Marcela ser bela ("nossa Grace } \\
\text { Kelly"), discreta, falar pouco e usar saias na altura do joelho. }\end{array}$ \\
& $\begin{array}{l}\text { Impossível não perceber que de fato a revista tenta fazer uma oposição ao que } \\
\text { Dilma representa. Uma mulher forte que sobreviveu à tortura durante a ditadura militar em } \\
\text { nosso país, e considerada pelos conservadores como fora do padrão imposto pela sociedade } \\
\text { de como uma mulher deve se comportar. }\end{array}$ \\
\hline \multirow{2}{*}{} &
\end{tabular}

No segundo argumento, é utilizado o exemplo da revista Veja, cuja reportagem tenta definir Marcela Temer, esposa de Michel Temer, como uma mulher padrão, que possui todas 


\section{S Linguagens}

as características de como uma mulher deve se comportar, honrando, assim, o nome da própria reportagem - A bela, recatada e do lar.

Todas essas características e, consequentemente, o estereótipo de mulher que elas constroem, conforme avalia Pretto, são uma tentativa da Revista de "fazer uma oposição ao que Dilma representa", uma mulher que vai contra o que a sociedade idealiza como "padrão". Com isso, ao citar e comentar a reportagem, mais uma vez o autor defende e comprova sua Tese de que o machismo tem sido utilizado para denegrir a figura da Presidenta.

Essa mesma ideia defendida nos Argumentos é reforçada na última etapa do texto, a Reiteração da Tese, reproduzida a seguir.

Fica claro que um homem, no lugar dela, não teria a capacidade questionada e nem sofreria ataques tão violentos como os que Dilma sofre simplesmente por ser mulher. Aliás, sempre que as mulheres se rebelam e não se submetem ao jugo masculino, são taxadas de loucas, descontroladas e histéricas. A mesma insubordinação em homens é vista como ato de coragem e firmeza.

A revista tenta glorificar Marcela Temer como mulher "padrão" que todas deveriam ser, à sombra de um homem e preparada para servir, nunca para comandar ou estar à frente dele. Defendemos que as mulheres têm o direito de levar a vida da forma como elas quiserem, na presidência da República ou no lar. O que não aceitamos é a difamação, a mentira e o discurso machista, misógino que tenta desconstituir o papel das mulheres.

Promover o empoderamento implica em uma série de mudanças em situações graves que vemos no dia a dia da sociedade e que afetam diretamente a vida e o direito de mulheres que são vítimas, e que morrem, por conta do machismo.

No primeiro parágrafo da Reiteração da Tese, é possível perceber uma retomada do que foi discutido no primeiro parágrafo do texto, que condiz com o estado emocional da Presidenta. Ao retomar, Edegar Pretto ressalta que, se o comportamento de Dilma fosse atribuído a uma figura masculina, seria algo positivo, evidenciando, mais uma vez, o machismo que circunda a Presidenta.

No último parágrafo do texto, apresenta-se uma suposta solução para o problema exposto no artigo de opinião - o machismo. Linguisticamente expressa pela construção "Promover o empoderamento implica em uma série de mudanças", a alternativa apresentada pelo autor funda-se no "empoderamento" das mulheres. Para alcançá-lo, porém, faz-se necessário que situações e comportamentos machistas presentes na sociedade sejam 


\section{Singuagens}

modificados, visando evitar que mulheres continuem tendo seus direitos cerceados e suas vidas prejudicadas.

Esse "empoderamento" perpassa ainda o direito de escolha das mulheres: as "mulheres têm direito de levar a vida como elas quiserem", "na presidência da República ou no lar". Como uma maneira de Reiterar e enfatizar sua Tese, Pretto defende que, independente da posição ocupada pela mulher e da opção que esta fizer, "a difamação, a mentira e o discurso machista, misógino que tenta desconstituir o papel das mulheres", assim como ocorre com a figura da Presidente Dilma, não pode ser aceito.

Em resumo, o autor defende, em sua Tese, que o machismo tem sido utilizado para atingir a Presidenta e, para sustentá-la, utiliza dois Argumentos que tomam como base reportagens de duas revistas brasileiras. Ao final, para reiterar a tese, Pretto reforça o machismo frente às situações vividas por Dilma Rousseff e apresenta uma possível solução para amenizar esse preconceito, revelando assim um propósito e uma estrutura que caracteriza o texto analisado como um exemplar do gênero exposição de opinião.

\section{CONSIDERAÇÕES FINAIS}

Este trabalho teve como objetivo analisar o gênero utilizado em um artigo de opinião a partir da aplicação de categorias da Teoria de Gênero e Registro. Com essa análise, verificamos que, da posição social de petista e, por conseguinte, aliado da Presidente da República, Edegar Pretto manifesta-se em favor de Dilma Rousseff e das mulheres em geral ao abordar o discurso e as investidas machistas como estratégias para atingir o governo e a então governante do Brasil. Com esse intuito, o autor sustenta sua Tese em dois Argumentos fundados em reportagens de duas conhecidas revistas brasileiras.

No texto, os conteúdos publicados pela Isto é e pela Veja funcionam como exemplos de situações concretas em que o machismo se manifesta e/ou é utilizado para denegrir a imagem da Presidenta e menosprezá-la a partir do reforço de estereótipos negativos construídos socialmente para as mulheres. Ao final do artigo de opinião, a Estrutura Esquemática do gênero exposição de opinião é complementada pela Reiteração da Tese, etapa em que o autor não apenas retoma seu ponto de vista frente ao machismo contra a Presidente, 


\section{S Linguagens}

mas também propõe uma possível solução para amenizar os problemas e o sofrimento causado por atitudes machistas na vida das mulheres.

\section{REFERÊNCIAS}

EGGINS, S.; MARTIN, J. R. Genre and registers of discourse. In: Van Dijk (Org). Discourse as structure and process. Discourse studies: a multidiscplinary introduction. London: SAGE Publications, 1999.

FARENCENA, G. S. Artigo de opinião como macrogênero: relações lógico-semânticas na perspectiva sistêmico-funcional. Santa Maria: UFSM, 2016. Tese (Doutorado em Letras), Universidade Federal de Santa Maria, Santa Maria, 2016.

FUZER, C.; GERHARDT, C.C.; GONÇALVES, A. A Linguística Sistêmico-Funcional em um processo de ensino e aprendizagem de leitura e escrita. In: III Jornada de Multiletramentos, V Jornada de Popularização da Ciência e II Encontro de Produção Textual, 2014, Santa Maria, RS. Caderno de Resumos, 2014. v. 1. p. 106-107.

GOUVEIA, C. A. M. Compreensão leitora como base instrumental do ensino da produção escrita. In: SILVA, W. R.; SANTOS, J. S. dos; MELO, M. A de. (Orgs.). Pesquisas em língua(gem) e demandas do ensino básico. Campinas, SP: Pontes Editores, 2014.

HALLIDAY, M. A. K. Part I. In: HALLIDAY, M.A.K \& HASAN, R. Language, context, and text: aspects of language in a social-semiotic perspective. Oxford: Oxford University Press, 1989.

Genre and Language Learning: a social semiotic perspective. Linguistic and Education, v. 20, n. $1,10-21,2009$.

MARTIN, J. M.; ROSE, D. Genre relations. London: Equinox, 2008.

MELO, J. M. de. Jornalismo opinativo: gêneros opinativos no jornalismo brasileiro. 3. ed. Campos do Jordão: Mantiqueira, 2003.

PRETTO, E. A bela, recatada e do lar. 2016. Disponível em: $<$ http://zh.clicrbs.com.br/rs/opiniao/noticia/2016/04/edegar-pretto-a-bela-ecatada-e-do-lar5786182.html >. Acesso em: 28 abr. 2016.

ROSE. D. Reading to Learn: selecting and analysing texts. Teacher training books and DVD. Sydney: Reading to Learn, 2011. 


\section{Linguagens \& Cidadania}

ROSE, D.; MARTIN, J. Learning to Write, Reading to Learn: Genre, Knowledge and Pedagogy in the Sydney School. Sheffield: Equinox, 2012.

SILVA, W. R.; ESPINDOLA, E. Afinal, o que é gênero textual na linguística sistêmicofuncional? Revista da Anpoll, n 34, Florianópolis, Jan./Jun. 2013, p. 259-307.

UBER, T. de J. B. Artigo de opinião: estudos sobre um gênero discursivo. 2008. Disponível em:<http://www.gestaoescolar.diaadia.pr.gov.br/arquivos/File/producoes_pde/artigo_terezinh a_jesus_bauer_uber.pdf $>$. Acesso em: 13 ago. 2013. 


\section{S Linguagens}

APÊEDICE - Estrutura Esquemática do gênero exposição de opinião no texto $A$ bela, recatada e do lar.

\begin{tabular}{|c|c|c|c|}
\hline & & & A bela, recatada e do lar \\
\hline & & & $\begin{array}{l}\text { aachismo também faz parte da estratégia para desconstituir a presidenta Dilma, eleita } \\
\text { tocraticamente por } 54 \text { milhões de brasileiros e brasileiras. }\end{array}$ \\
\hline & & & $\begin{array}{l}\text { Desde a campanha eleitoral, Dilma sofre ataques machistas. Algumas semanas atrás nos } \\
\text { revoltamos com matéria da revista Isto é, que afirmava que a presidenta estava } \\
\text { desequilibrada e sem condições emocionais para conduzir o país, inclusive quebrando } \\
\text { móveis dentro do palácio. } \\
\text { A revista reforçou que mulheres são descontroladas emocionalmente, e portanto não estão } \\
\text { preparadas para exercer o poder político. Quando o assunto é política, as mulheres têm } \\
\text { pouco espaço para serem ouvidas, e são comuns os casos de machismo e preconceito. }\end{array}$ \\
\hline 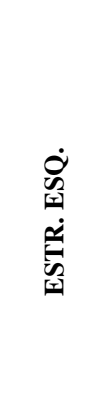 & $\bar{E}$ & 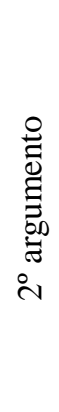 & $\begin{array}{l}\text { Após a votação do impeachment da presidenta Dilma na Câmara dos Deputados, onde } \\
\text { também assistimos muitas falas misóginas, a revista Veja publicou reportagem com } \\
\text { Marcela Temer, esposa de Michel Temer, e já na manchete a definiu como bela, recatada e } \\
\text { do lar. O texto tinha aparente pretensão de elogio ao fato de Marcela ser bela ("nossa } \\
\text { Grace Kelly"), discreta, falar pouco e usar saias na altura do joelho. } \\
\\
\text { Impossível não perceber que de fato a revista tenta fazer uma oposição ao que Dilma } \\
\text { representa. Uma mulher forte que sobreviveu à tortura durante a ditadura militar em nosso } \\
\text { país, e considerada pelos conservadores como fora do padrão imposto pela sociedade de } \\
\text { como uma mulher deve se comportar }\end{array}$ \\
\hline & & & $\begin{array}{l}\text { Fica claro que um homem, no lugar dela, não teria a capacidade questionada e nem } \\
\text { sofreria ataques tão violentos como os que Dilma sofre simplesmente por ser mulher. } \\
\text { Aliás, sempre que as mulheres se rebelam e não se submetem ao jugo masculino, são } \\
\text { taxadas de loucas, descontroladas e histéricas. A mesma insubordinação em homens é } \\
\text { vista como ato de coragem e firmeza. } \\
\text { A revista tenta glorificar Marcela Temer como mulher "padrão" que todas deveriam ser, à } \\
\text { sombra de um homem e preparada para servir, nunca para comandar ou estar à frente dele. } \\
\text { Defendemos que as mulheres têm o direito de levar a vida da forma como elas quiserem, } \\
\text { na presidência da República ou no lar. O que não aceitamos é a difamação, a mentira e o } \\
\text { discurso machista, misógino que tenta desconstituir o papel das mulheres. } \\
\text { Promover o empoderamento implica em uma série de mudanças em situações graves que } \\
\text { vemos no dia a dia da sociedade e que afetam diretamente a vida e o direito de mulheres } \\
\text { que são vítimas, e que morrem, por conta do machismo. }\end{array}$ \\
\hline
\end{tabular}

